\title{
In Situ Scanning Electron Microscopy Study of Fatigue Crack Propagation
}

\author{
L. Jacobsson, ${ }^{1, a}$ C. Persson, ${ }^{1, b}$ and S. Melin ${ }^{2, c}$ \\ ${ }^{1}$ Division of Materials Engineering, Lund University, Lund, Sweden \\ ${ }^{2}$ Division of Mechanics, Lund University, Lund, Sweden \\ ${ }^{a}$ lars.jacobsson@material.lth.se, ${ }^{\mathrm{b}}$ christer.persson@material.lth.se, ${ }^{\mathrm{c}}$ solveig.melin@mek.lth.se
}

The fatigue crack propagation rate is influenced by various mechanisms at the very vicinity of the crack tip, e.g., local plasticity and/or creep, microcracking, crack branching, and crack closure induced by plasticity and roughness. To study these mechanisms and their influence on crack propagation rate during different loadings, in situ scanning electron microscope studies have been performed. Throughout the load cycles images were taken and analyzed with an image analysis technique to measure the displacements around the crack tip. The obtained data can be used to determine compliance curves at any point along the crack, crack shapes, and the displacement field in the crack tip vicinity. The technique has been used to analyze which mechanisms of crack propagation are realized during, e.g., fatigue with overloads, and thermomechanical fatigue. The results were compared with results from measurements using the direct current potential drop technique, and it was found that various load conditions promote different mechanisms for crack propagation.

Keywords: fatigue, crack propagation, scanning electron microscope, crack shape, crack closure, potential drop.

Introduction. It is of interest to study the material in the crack tip vicinity to understand the effects of material plasticity around the crack tip, roughness of the crack faces, microstructure, stresses, and deformations, on the crack propagation. Elber $[1,2]$ introduced the concept of crack closure where the maximum stress level at the crack tip is critical. The maximum load, is calculated from the closure level, where the crack tip is under zero load, and the applied stress intensity factor range. To measure the crack closure load level, a number of different measurement techniques are used. Song and Shieh [3] used the direct current potential drop technique to find the crack closure level, whereas the ASTM E647-99 [4] recommends to apply the crack mouth opening displacement. Also, there are different techniques using microscope images to measure the displacements along the crack.

The aim of this study was to determine the deformations along the crack, and how the deformations are affected by the different crack propagation mechanisms. High resolution images from an in-situ scanning electron microscope was used to measure deformations at the crack tip vicinity, and the potential drop technique was used to measure the contact between the crack surfaces.

Experimental Setup. The fatigue crack propagation experiments were performed within a scanning electron microscope (SEM), using a small electrically driven load stage to perform the load cycles, also described by Andersson et al. [5]. The test specimens had dimensions of $70 \times 10 \mathrm{~mm}$ and were cut from $0.5 \mathrm{~mm}$ Inconel 718 foil. The specimens were prepared with a single-edge-notch tension (SENT) crack, that was pre-cracked in a servohydraulic load frame to a length of $0.7-1.0 \mathrm{~mm}$. The specimens were etched to produce a recognizable pattern on the surface of the specimen for the SEM observations. The specimens were prepared with thin wires welded at the crack mouth to measure the electrical potential drop signal over the crack. A direct current of $1.0 \mathrm{~A}$ was passed through the specimen and the potential drop signal was amplified before saved in the computer. The crack propagation rate and the crack closure level were determined. A summary of the performed experiments is found in Table 1. 
Experimental Conditions for the Four Crack Propagation Experiments

\begin{tabular}{|c|c|c|c|c|}
\hline Experiment & $a, \mu \mathrm{m}$ & $\Delta K, \mathrm{MPa} \cdot \mathrm{m}^{1 / 2}$ & $\Delta K_{\text {eff }}, \mathrm{MPa} \cdot \mathrm{m}^{1 / 2}$ & $R=\sigma_{\min } / \sigma_{\max }$ \\
\hline i $\boldsymbol{\square}$ & 740 & 16.6 & 3.1 & 0.01 \\
\hline ii $\boldsymbol{\nabla}$ & 945 & 19.7 & 10.0 & 0.01 \\
\hline iii $\boldsymbol{\Delta}$ & 1673 & 43.3 & 26.3 & 0.01 \\
\hline iv & 1764 & 65.0 & 42.0 & 0.02 \\
\hline
\end{tabular}

Image Analysis Method. A new image analysis method was developed to measure displacements in the crack tip vicinity from high resolution SEM images. Images were taken along the crack throughout the loading cycles. The displacements between different images were determined using a cross-correlation function that recognized a selected area of one image in another image, taken at a different load. The area was placed within $2-10 \mu \mathrm{m}$ from the crack, where the deformation within the material was negligible. Compliance curves and crack shapes were determined from the measured displacement field.

Results and Discussion. Crack shapes and compliance curves were determined during a number of experiments with different loading histories. Compliance curves from points at different distances from the crack tip are compared in Fig. 1. The compliance curve measured at the crack mouth showed negligible influence from the plastic zone, and had a small knee at a higher load than the compliance curves measured at the crack tip, that showed clear effects from the plastic zone and closure of the crack surfaces. The knee on the curves from the potential drop (PD) measurements showed in Fig. 2a, indicates the closure level. Above this level the crack was fully open and the change in electrical conductivity was only due to the high stresses in front of the crack, and below this level the contact between the crack surfaces increased with decreasing load. The load level at the knee on the PD-curves was higher than that at the knee on the compliance curves measured at the crack mouth.

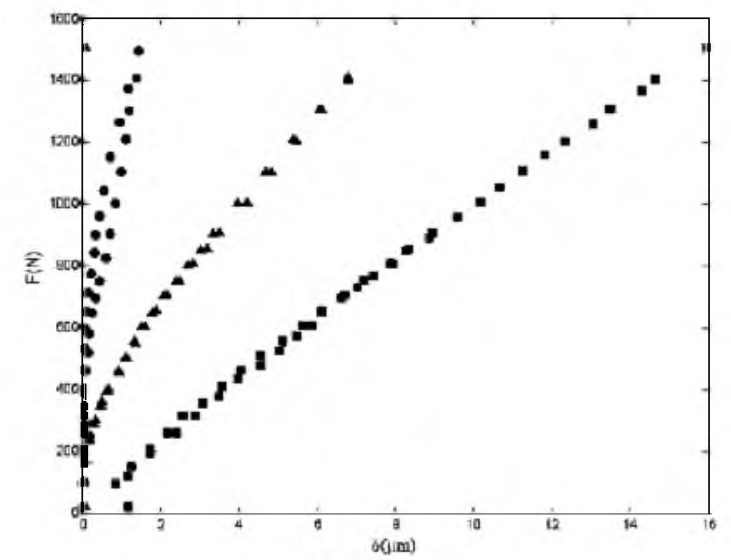

Fig. 1. Compliance curves measured at three different distances from the crack tip: (๑) $2 \mu \mathrm{m}$; (A) $20 \mu \mathrm{m} ;(\boldsymbol{Q})$ at the crack mouth

The crack shape obtained by linear elastic fracture mechanics (LEFM) considerations does not always describe the true crack shape well because of the influence from the plastic zone and the microstructure. The LEFM solutions, as well as crack shapes compensated for closure levels from compliance curves and PD measurements, are shown in Fig. 3. The LEFM solution will be the same, independent of the closure level when the 


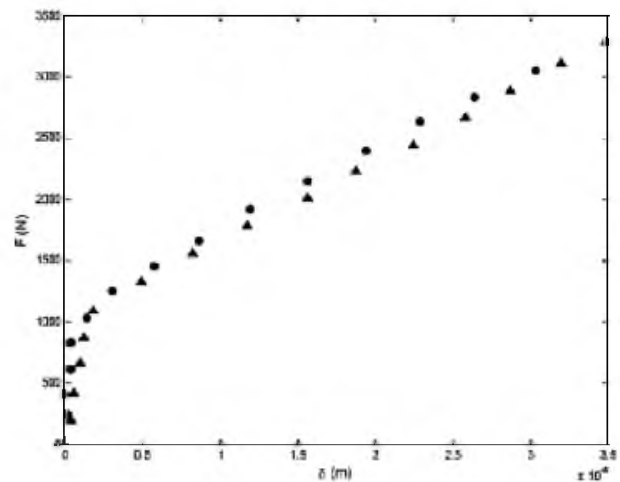

a

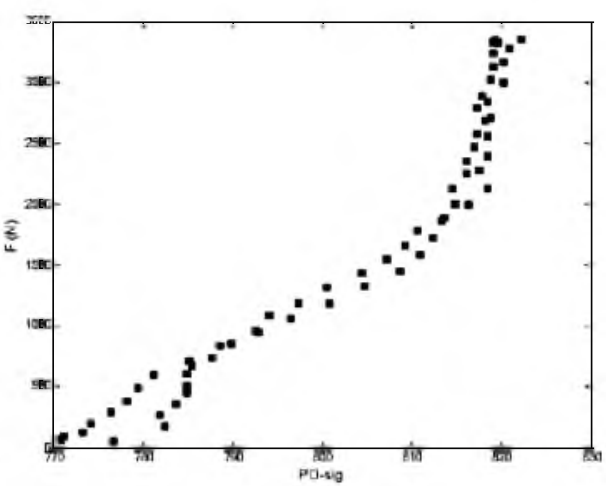

b

Fig. 2. Compliance curve with closure level at $1200 \mathrm{~N}$ (a) and the corresponding PD-curve with closure level at $1700 \mathrm{~N}$ (b) for $K_{\max }=65 \mathrm{MPa} \cdot \mathrm{m}^{1 / 2}, R=0.02$, overload ratio $1.26, a=1.8 \mathrm{~mm}$, specimen thickness $0.5 \mathrm{~mm}$, and displacements measured $15 \mu \mathrm{m}$ from the crack tip. (Experiment iv.)

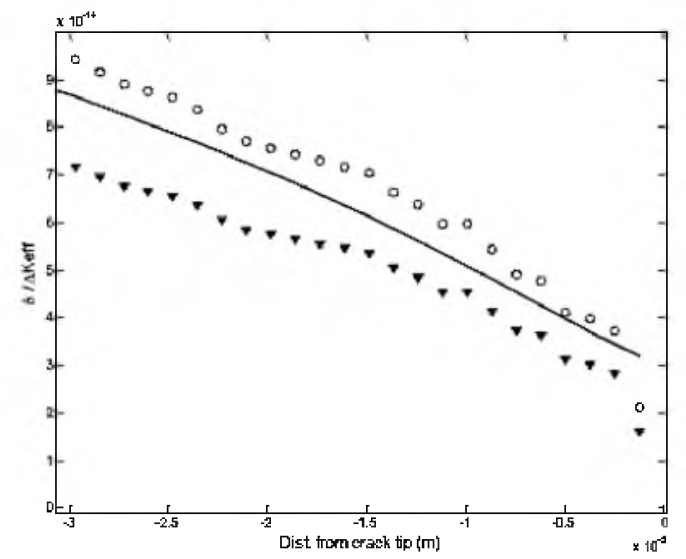

Fig. 3. Experimental results are compensated for the effective stress intensity factor range measured from the compliance curve $(\boldsymbol{\nabla})$ and from the PD signal $(O)$. (Experiment iv. The opening displacements divided by the effective stress intensity factor range. The solid line shows the LEFM solution.)

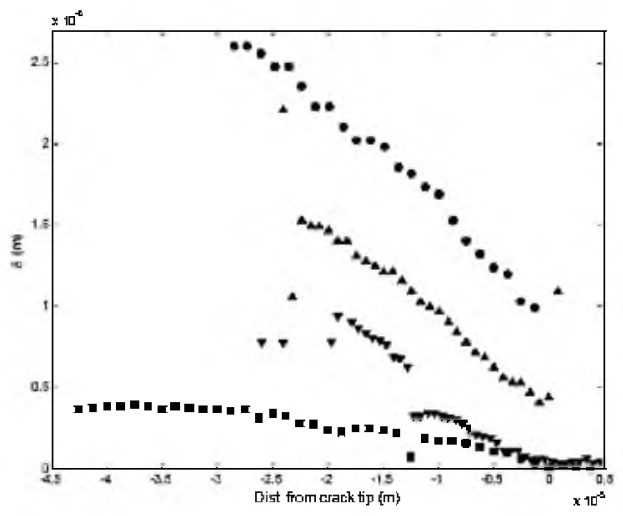

a

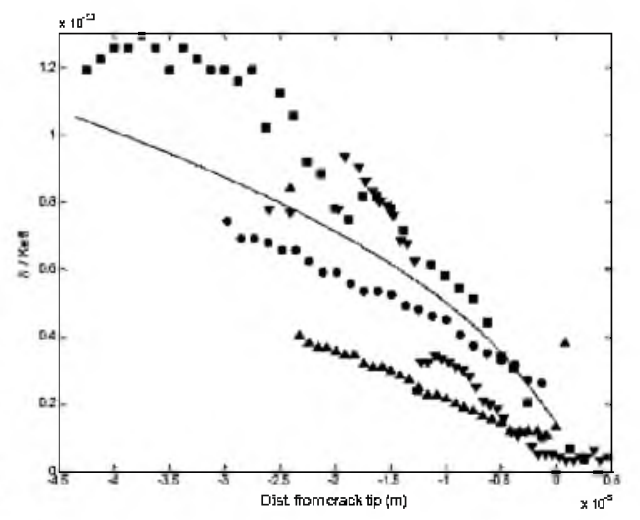

b

Fig. 4. Crack shapes (a) and $\delta$-deformations (b) divided by effective stress intensity factor range versus distance from crack tip for the four experiments. (Solid line is the LEFM solution.) 
displacement divided by the effective stress intensity factor range is plotted. When the experimental results were divided by the closure levels measured from the compliance curves and the PD-curves, the results diverged (Fig. 3).

In Fig. 4a, the crack shapes are plotted for four different experiments (Table 1). This close to the crack tip, the microstructure and the change in crack direction affects the crack shape. In Fig. 4b, the deformation was divided with the effective stress intensity factor found from compliance curves. The results showed similarities between the four experiments and also the LEFM solution was close to the experimental results. The crack tip is shown in Fig. 5.

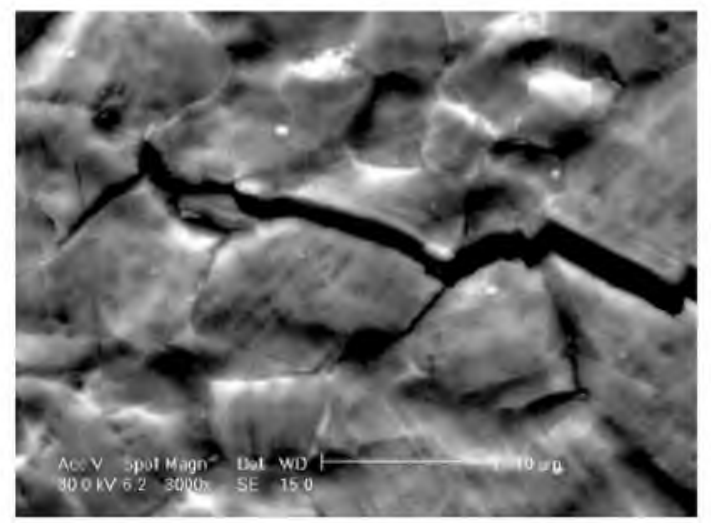

Fig. 5. SEM image of the crack tip at maximum load. (Experiment iii.)

Conclusions. Experiments have been performed within a SEM and the images were used to determine deformations in the vicinity of the crack tip. Compliance curves were determined and compared with results from PD measurements. The PD measurements gave higher values for the crack closure load than the compliance measurements. When the experimental results, compensated for crack closure were compared with the LEFM solution, the crack shapes at the crack tip vicinity became comparable even when the crack shapes were irregular due to the microstructural variations.

Acknowledgments. The authors give their acknowledgements to the Swedish Gas Turbine Center for the financial support.

1. W. Elber, Eng. Fract. Mech., 2, 37-45 (1970).

2. W. Elber, in: Damage Tolerance in Aircraft Structures, ASTM STP 486 (1971), pp. 230-242.

3. P. S. Song and Y. L. Shieh, Int. J. Fatigue, 26, 429-436 (2004).

4. Standard Test Method for Measurement of Fatigue Crack Growth Rates, ASTM E647-99 (1995).

5. M. Andersson, C. Persson, and S. Melin, Int. J. Fatigue, 28, 1059-1068 (2006).

Received 28. 06. 2007 